\title{
Extrasynaptic and postsynaptic receptors in glycinergic and GABAergic neurotransmission: a division of labor?
}

\author{
Emilie Muller ${ }^{1,2, \uparrow}$, Hervé Le-Corronc ${ }^{1}$ and Pascal Legendre ${ }^{1, *}$ \\ 1. UMR 7102 - Neurobiologie des Processus Adaptatifs, Université Pierre et Marie Curie, Paris, France \\ 2. Ottawa Health Research Institute, Ottawa, ON, Canada
}

Edited by: Jochen C. Meier, Max Delbrück Center for Molecular Medicine, Germany

Reviewed by: Rosemarie Grantyn, Humboldt University Medical School, Germany

\begin{abstract}
Glycine and GABA mediate inhibitory neurotransmission in the spinal cord and central nervous system. The general concept of neurotransmission is now challenged by the contribution of both phasic activation of postsynaptic glycine and GABA receptors $(G l y R s$ and $G_{A B A} R$ s, respectively) and tonic activity of these receptors located at extrasynaptic sites. GlyR and $G_{A} A B A_{A} R$ kinetics depend on several parameters, including subunit composition, subsynaptic localization and activation mode. Postsynaptic and extrasynaptic receptors display different subunit compositions and are activated by fast presynaptic and slow paracrine release of neurotransmitters, respectively. GlyR and $\mathrm{GABA}_{\mathrm{A}} \mathrm{R}$ functional properties also rely on their aggregation level, which is higher at postsynaptic densities than at extrasynaptic loci. Finally, these receptors can co-aggregate at mixed inhibitory postsynaptic densities where they cross-modulate their activity, providing another parameter of functional complexity. GlyR and GABA $R$ density at postsynaptic sites results from the balance between their internalization and insertion in the plasma membrane, but also on their lateral diffusion from and to the postsynaptic loci. The dynamic exchange of receptors between synaptic and extrasynaptic sites and their functional adaptation in terms of kinetics point out a new adaptive process of inhibitory neurotransmission.
\end{abstract}

Keywords: glycine receptors, $\mathrm{GABA}_{\mathrm{A}}$ receptors, postsynaptic, extrasynaptic, lateral diffusion, aggregation, cross-talk, presynaptic

\section{INTRODUCTION}

The idea that, in the adult, non-synaptic release of neurotransmitters occurs in addition to classical release from presynaptic terminals, gains more significance in recent years. Accordingly, the contribution of both synaptic and extrasynaptic receptors to neuronal activity extends the general concept of neurotransmission. Recent findings demonstrated that the density of receptors at postsynaptic sites does not solely depend on the balance between their internalization and insertion in the plasma membrane, but also on their lateral diffusion from and to the postsynaptic loci (Bruneau and Akaaboune, 2006; Kneussel and Loebrich, 2007; Triller and Choquet, 2005). These observations introduced the new notion that receptor accumulation at postsynaptic loci is a dynamic process, resulting from receptor oscillation between a diffuse state at extrasynaptic sites and a more confined state within the postsynaptic density. While this has been first demonstrated for N-Methyl-D-Aspartate receptors (NMDARs) at glutamatergic excitatory synapses, it was also recently shown to occur at inhibitory synapses.

Glycine and GABA are the main inhibitory neurotransmitters in the central nervous system (CNS) of vertebrates. They activate two distinct

*Correspondence: Pascal Legendre, UMR 7102 - Neurobiologie des Processus Adaptatifs, Université Pierre et Marie Curie, Bat. B, 6e, Case 1, 9, Quai Saint Bernard 75252 Paris CEDEX 05, France. e-mail: pascal.legendre@snv.jussieu.fr

Present address: E. Muller, Ottawa Health Research Institute, 725 Parkdale Avenue, Ottawa, 0N, K1Y4E9, Canada.

Received: 23 January 2008; paper pending published: 29 January 2008; accepted: 30 January 2008; published online: 28 March 2008

Citation: Front. Mol. Neurosci. (2008) 1: 3. doi: 10.3389/neuro.02.003.2008

Copyright () 2008 Muller, Le-Corronc and Legendre. This is an open-access article subject to an exclusive license agreement between the authors and the Frontiers Research Foundation, which permits unrestricted use, distribution, and reproduction in any medium, provided the original authors and source are credited. families of ionotropic ligand-gated chloride channels, glycine receptors (GlyRs) (Legendre, 2001) and GABA receptors (GABA Rs) (Macdonald and Olsen, 1994), which accumulate at postsynaptic sites to allow effective fast inhibitory neurotransmission. The postsynaptic aggregation and stabilization of GlyRs and $\mathrm{GABA}_{A}$ Rs require interactions with intracellular anchoring proteins, which are part of a subsynaptic protein scaffold linked to the cytoskeleton (Legendre, 2001). In the recent years, however, it has become apparent that inhibitory receptors are not necessarily facing presynaptic terminals. During synaptogenesis and even in the adult, GlyRs and $\mathrm{GABA}_{A} \mathrm{Rs}$ are localized both at extrasynaptic and postsynaptic sites. These receptors are likely to display different functional properties, according to their subcellular distribution. Indeed, it is now well established that postsynaptic receptors are mostly responsible for fast and phasic neurotransmission while activation of extrasynaptic receptors would rather be involved in slow and tonic modulation of neuronal activity. Moreover, several evidences indicate that even inhibitory receptors trapped at postsynaptic loci can have different functional properties, depending on their aggregation level. Thus, the functional properties of inhibitory GlyRs and $\mathrm{GABA}_{A}$ Rs will vary as a function of their subcellular.

Despite these functional differences, glycinergic and GABAergic synapses display morphological similarities. Glycine and GABA notably share the same presynaptic vesicular transporter (the vesicular inhibitory amino acid transporter VIAAT) (Dumoulin et al., 1999; Sagné et al., 1997) while the anchoring protein gephyrin is involved in the aggregation and postsynaptic stabilization of both GlyRs and GABA $_{A} R s$ (Legendre, 2001). Accordingly, it is now well established that glycinergic and GABAergic neurotransmission can be intermingled to provide inhibition of neuronal activity. Indeed, in the spinal cord and several distinct brainstem areas, glycine and GABA can be co-released from the same presynaptic terminal to activate postsynaptic GlyRs and $\mathrm{GABA}_{A} \mathrm{Rs}$, as demonstrated by recording mixed miniature inhibitory postsynaptic currents. Interestingly, 
recent findings indicate that the co-activation of GlyRs and $\mathrm{GABA}_{A} \mathrm{Rs}$ at mixed inhibitory synapses does not simply display a summation of currents mediated by both receptor subtypes, resulting from functional cross-talk between these co-aggregated postsynaptic receptors.

The purpose of this review is to present a coherent synthesis of recent findings focusing on the variability of GlyR and $\mathrm{GABA}_{A} \mathrm{R}$ functional properties, depending on their postsynaptic/extrasynaptic localization, their aggregation level and/or their level of interaction. In particular, the possible functional significance of this variability will be discussed.

\section{MOLECULAR HETEROGENEITY OF GlyRs AND GABA $A s$}

As nicotinic acetylcholine and 5-hydroxytryptamine type 3 receptors, GlyRs and GABA Rs belong to the cystein-loop receptor family (Lynch, 2004). GlyRs and $G A B A_{A} R s$ are pentameric assemblies of subunits, whereby each subunit contains four transmembrane domains (TM1-TM4). The transmembrane domain TM2 forms the channel pore permeable to chloride ions. Subunit expression is developmentally regulated and varies depending on the brain region studied (Lynch, 2004; Mohler et al., 1995; Paysan and Fritschy, 1998).

\section{GlyR composition}

GlyRs are composed of $\alpha(1-4)$ and $\beta$ subunits which assemble to form $\alpha(2) \beta(3)$ heteromeric or $\alpha(5)$ homomeric receptors. The agonist binding site is mainly carried by the $\alpha$ subunit (Lynch, 2004) while the $\beta$ subunit binds the anchoring protein gephyrin with high affinity (Kirsch and Betz, 1993; Meyer et al., 1995). GlyR subunits are differentially expressed depending on the brain area studied. In the adult, heteromeric $\alpha 1 \beta$ GlyRs are predominant and uniformly expressed in the CNS, while the expression of the $\alpha 2$ subunit has been mainly detected in the cortex the olfactory bulb, the thalamus, the central gray matter, the retina and the hippocampus (Malosio et al., 1991; Sato et al., 1992). The expression of the $\alpha 3$ subunit is restricted to the spinal cord ventral horn, the cerebellum, the olfactory bulb and the retina (Malosio et al., 1991). Finally, the $\alpha 4$ subunit is predominantly expressed in the inner plexiform layer of the retina (Heinze et al., 2007).

In addition to their regional distribution, GlyR subunit expression has been shown to be developmentally regulated (Lynch, 2004). The $\alpha 2$ subunit is already detected at the onset of synaptogenesis in the developing CNS, followed by the expression of $\beta, \alpha 1$ and $\alpha 3$ subunits around birth. The expression of $\alpha 1$ and $\alpha 3$ subunits progressively increases during the first postnatal weeks while the expression of the $\alpha 2$ subunit decreases to reach a basal level during the same period. Thus, it is assumed that immature GlyRs would be homomeric $\alpha 2$ receptors, progressively replaced by $\alpha 2 \beta$ heteromeric GlyRs and then by $\alpha 1 \beta$ and $\alpha 3 \beta$ heteromeric GlyRs. This developmental pattern has been determined in the spinal cord and several brainstem nuclei of rodents (Malosio et al., 1991; Piechotta et al., 2001; Singer et al., 1998).

The diversity of GlyR subunits is increased by the alternative splicing of $\alpha 1, \alpha 2$ and $\alpha 3$ subunits (Kuhse et al., 1991; Malosio et al., 1991; Nikolic et al., 1998). Interestingly, $\alpha 2$ - or $\alpha 3$-containing GlyRs display strong differences in their functional properties depending on splice variants. In case of the $\alpha 2$ subunit, two alternative splice variants were detected, namely the $\alpha 2 A$ and the $\alpha 2 B$ subunits (Kuhse et al., 1991). Compared to the $\alpha 2 A$ subunit, $\alpha 2 B$ contains an isoleucine (instead of valine) at position 58 and an alanine (instead of threonine) at position 59. From a functional point of view, $\alpha 2 A$-containing GlyRs display a lower potency for glycine (higher $\mathrm{EC}_{50}$ value) than those containing the $\alpha 2 \mathrm{~B}$ subunit. In case of the $\alpha 3$ subunit, two alternative splice variants, namely $\alpha 3 \mathrm{~K}$ and $\alpha 3 \mathrm{~L}$, were isolated from human fetal brain (Nikolic et al., 1998). Compared to the $\alpha 3 \mathrm{~K}$ variant, $\alpha 3 \mathrm{~L}$ contains an additional sequence of 15 amino acids, inserted within the cytoplasmic loop that connects transmembrane domains TM3 and TM4 (Nikolic et al., 1998). Interestingly, this alternative insert contains a consensus amino acid sequence for casein kinase-II dependent phosphorylation (serine at position 370) (Nikolic et al., 1998). Functionally, $\alpha 3 \mathrm{~L}$-containing GlyRs desensitize more slowly than those containing the $\alpha 3 \mathrm{~K}$ subunit. These results clearly show that alternative splicing alters the functional properties of GlyRs.

\section{Large diversity of $\mathrm{GABA}_{\mathrm{A}} \mathrm{Rs}$}

In contrast to GlyRs, $\mathrm{GABA}_{A}$ Rs are composed of a large variety of different subunits. Indeed, nineteen $\mathrm{GABA}_{A} \mathrm{R}$ subunits have been cloned so far $(\alpha 1-6, \beta 1-3, \gamma 1-3, \delta, \varepsilon, \theta, \pi$ and $\rho 1-3$; the $\rho 1-3$ subunits can also be part of $\mathrm{GABA}_{c}$ receptors) (Macdonald and Olsen, 1994). While theoretically this subunit diversity allows for many different subunit combinations, only a dozen were detected so far (Farrant and Nusser, 2005). The most abundantly expressed GABA $R$ in the CNS is composed of two $\alpha 1$, two $\beta$ and one $\gamma 2$ subunit. The agonist binding site is carried mainly by the $\alpha$ subunits, while the $\gamma$ subunits are responsible for linking $G_{A B A}$ Rs to the postsynaptic cytoskeleton. Similarly to GlyRs, $\mathrm{GABA}_{A} \mathrm{R}$ subunit expression is developmentally regulated (Paysan and Fritschy, 1998) and depends on the brain area studied (Wisden et al., 1992). Finally, as for GlyRs, the diversity of GABA $R$ subunits is increased by alternative splicing (Farrant and Nusser, 2005).

\section{CORRESPONDENCE BETWEEN GIYR AND GABA R SUBCELLULAR DISTRIBUTIONS AND SUBUNIT COMPOSITIONS}

\section{Homomeric and heteromeric GlyRs}

The GlyR $\beta$ subunit directly binds gephyrin, which immobilizes postsynaptic GlyRs through gephyrin-mediated anchoring at the subsynaptic cytoskeleton. Thus, heteromeric $\alpha \beta$ GlyRs are expected to be mainly postsynaptically located, although it has been suggested that GlyRs and gephyrin could bind before GlyR insertion into postsynaptic sites (Hanus et al., 2004). To the contrary, homomeric $\alpha$ GlyRs, which do not contain the $\beta$ subunit, are expected to freely diffuse in the plasma membrane rather than to accumulate at postsynaptic densities, thus representing extrasynaptic GlyRs. However, low-affinity interactions between the $\alpha 2$ subunit and gephyrin suggest that homomeric $\alpha 2$ GlyRs could also aggregate at postsynaptic loci (Takagi et al., 1992). Indeed, synaptic currents displaying functional characteristics of homomeric GlyRs have been recorded from the hindbrain of zebrafish larvae (Legendre, 1997), suggesting that these receptor subtypes could also be synaptically activated.

\section{Extrasynaptic localization of GABA $A_{A}$ : $\alpha 5$ and $\delta$ subunits}

GABA $_{A}$ Rs composed of $\alpha 1-4, \alpha 6, \beta 2 / 3$ or $\gamma 2$ subunits can be found both at postsynaptic loci and at extrasynaptic sites, albeit at lower density (Fritschy et al., 1992; Nusser et al., 1995). The $\gamma 2$ subunit appears to be essential for postsynaptic accumulation of GABA Rs (Essrich et al., 1998; Sassoè-Pognetto et al., 1995; Sur et al., 1995). Therefore, replacement of the $\gamma 2$ subunit by the $\delta$ subunit may have a profound impact on the subcellular localization of $\mathrm{GABA}_{\mathrm{A}} \mathrm{Rs}$. Indeed, $\alpha 4 \beta \delta$ and $\alpha 6 \beta \delta \mathrm{GABA}_{\mathrm{A}} \mathrm{Rs}$ were found exclusively at extrasynaptic sites (Nusser et al., 1998). Moreover, the $\alpha 5$ subunit also seems to contribute to the pool of extrasynaptic receptors because in hippocampal pyramidal cells these $\mathrm{GABA}_{\mathrm{A}} \mathrm{Rs}$ are found diffusely distributed and do not co-localize with postsynaptic gephyrin (Brünig et al., 2002). Accordingly, it was postulated that the $\alpha 5$ subunit prevents $\mathrm{GABA}_{\mathrm{A}} \mathrm{Rs}$ from postsynaptic accumulation by impairment of the $\gamma$ 2-gephyrin interaction interface (Crestani et al., 2002).

\section{SYNAPTIC AND NON-SYNAPTIC RELEASE OF GLYCINE AND GABA}

GlyRs and $\mathrm{GABA}_{\mathrm{A}}$ Rs display different functional properties according to whether they are accumulated at postsynaptic densities or diffuse at extrasynaptic sites. To some extend, these differences result from different receptor activation modes, according to fast presynaptic or slow paracrine neurotransmitter release. 


\section{Presynaptic release and fast inhibitory transmission}

Fast synaptic transmission is mediated by the transient activation of postsynaptic receptors, which allows the conversion of presynaptic activity into postsynaptic signals that shape the activity of the postsynaptic cell. When an action potential reaches the presynaptic terminal, a local calcium influx rapidly increases the release probability of presynaptic vesicles. In case of inhibitory synapses, each vesicle can release a large number (several thousands) of GABA and/or glycine molecules into the synaptic clef in a very short time interval. Consequently, the neurotransmitter concentration in the vicinity of postsynaptic receptors increases quickly and allows their synchronous activation or opening. Neurotransmitter clearance either by diffusion out of the synaptic cleft or by re-uptake through specific transporter proteins then stops receptor activation.

Thus, particular features of phasic synaptic transmission are the short duration and the transient high neurotransmitter concentrations within the synaptic cleft. In fact, using low-affinity competitive $G_{A B A_{A} R}$ antagonists, the decay time constant of GABA clearance from the synaptic cleft was estimated to be $\sim 100$ microseconds (Barberis et al., 2004; Mozrzymas et al., 1999). This parameter has not been determined for glycinergic phasic synaptic transmission. However, according to the simple geometry of glycinergic synaptic clefts (Vannier and Triller, 1997), to the diffusion coefficient of glycine and to the lack of effect of glycine re-uptake inhibitors on the time course of glycinergic synaptic events (Titmus et al., 1996), synaptic glycine clearance is likely to be as fast as synaptic GABA clearance.

Another important parameter modulating postsynaptic receptor activation is their occupancy level by neurotransmitters released from presynaptic terminals. The occupancy level at individual postsynaptic site was investigated at glycinergic synapses in the hindbrain of zebrafish (Rigo et al., 2003) as well as at GABAergic synapses formed between basket and stellate interneurons in the cerebellum (Auger and Marty, 1997). In both studies, application of $\alpha$-Latrotoxin (a neurotoxin purified from black widow spider venom) triggered massive vesicular neurotransmitter release at active zones and induced bursts of miniature synaptic events that apparently originated at single release sites. The postsynaptic receptor occupancy level was then extracted from miniature postsynaptic current analysis. Although in some cases, postsynaptic receptors were saturated by the release of a single vesicle, the occupancy level was shown to strongly vary between individual synaptic sites and even at the same synapse, which is due to variations in the number of neurotransmitter molecules released per vesicle.

\section{Paracrine release and tonic inhibitory transmission}

While phasic activation of postsynaptic GlyRs and $G_{A B A}$ Rs has been considered for decades to represent the main activation mode of inhibitory receptors, recent reports provide strong evidence for a slower receptor activation when located at extrasynaptic sites. These observations point to a tonic activation of extrasynaptic receptors, which is very likely to also contribute to inhibitory neurotransmission. The slow time course of extrasynaptic receptor activation can be explained by spillover of neurotransmitters from the synaptic cleft and by paracrine release of neurotransmitters from adjacent non-neuronal cells. Indeed, neurotransmitters released from astrocytes through vesicular dependent pathways were shown to modulate synaptic activity (Evanko et al., 2004). In fact, glycine uptake into synaptosomes through glycine transporters was shown to mediate carrier-dependent release of GABA (Raiteri et al., 2001), and since these transporters are expressed by astrocytes, a reverse activity of specific re-uptake transporters could provide a mechanism for non-synaptic release of neurotransmitters and modulation of inhibitory transmission through tonic receptor activation.

Slow activation of $\mathrm{GABA}_{\mathrm{A}} \mathrm{Rs}$ has been extensively studied and recently reviewed by Farrant and Nusser (Farrant and Nusser, 2005). Continuous or tonic activation of $\mathrm{GABA}_{A} \mathrm{Rs}$ occurs before and during synaptogenesis at embryonic stages (LoTurco et al., 1995). However, this tonic activation has also been demonstrated at more mature stages in thalamocortical neurons (Cope et al., 2005), in the hippocampal dentate gyrus, cerebellar granule cells (Brickley et al., 1996), in pyramidal neurons from the fifth layer of the somatosensory cortex (Salin and Prince, 1996), as well as in pyramidal cells and interneurons in the CA1 region of the hippocampus (Bieda and Maclver, 2004; Marchionni et al., 2007). Spillover of GABA in response to high presynaptic activity can slowly activate peri-synaptic $\mathrm{GABA}_{\mathrm{A}} \mathrm{Rs}$, reinforcing inhibitory GABAergic transmission. In the dentate gyrus of the hippocampus, however, vesicular release of GABA does not play a role in tonic $\mathrm{GABA}_{\mathrm{A}} \mathrm{R}$ activation (Carta et al., 2004), suggesting a paracrine release of unknown origin and mechanism. Indeed, it was proposed that GABA re-uptake transporters, which usually remove GABA from the extracellular space, could function in a reverse manner depending on the sodium gradient in their vicinity, thereby providing ambient GABA responsible for continuous $\mathrm{GABA}_{A} \mathrm{R}$ activation (Attwell et al., 1993). However, this hypothesis has been challenged by studies describing an increase in the amplitude of GABA-mediated tonic currents in the presence of GABA re-uptake inhibitors (Jensen et al., 2003) as well as in mice deficient for these transporters (Wall and Usowicz, 1997).

Tonic activation of GlyRs is less documented than that of $G_{A B A} R s$. Rather than glycine, the endogenous GlyR agonist taurine appears to be involved in tonic activation of extrasynaptic GlyRs both at embryonic and adult stages. High taurine levels are detected in non-neuronal cells, such as astrocytes (Dutton et al., 1991), in immature neurons (Flint et al., 1998), as well as in specific neuronal subtypes like Purkinje cells in the cerebellum (Madsen et al., 1985). Initially, a non-synaptic release of taurine, sensitive to hypo-osmotic shock, was described in the immature cortex of mice. Although the release mechanism was not investigated in this study, the main source of taurine was discussed to be immature cortical neurons (Flint et al., 1998). While the concentration of taurine present in the immature cortex is not known, it was estimated to be $\sim 0.3 \mathrm{mM}$, which roughly corresponds to the $\mathrm{EC}_{50}(1.1 \mathrm{mM})$ of GlyRs expressed by these neurons (Flint et al., 1998). Another example of non-synaptic hypoosmotic- or high-potassium-sensitive taurine release was described in the neurohypophysis. Furthermore, taurine release from pituicytes was shown to activate GlyRs expressed by supraoptic neurons, inhibiting vasopressin neuronal release (Hussy et al., 2001). Finally, while a few glycine-immunostained fibers were detected in the substancia nigra pars compacta (Rampon et al., 1996), taurine is assumed to be the major endogenous GlyR agonist in this brain area (Doretto et al., 1994; Häusser et al., 1992; Rampon et al., 1996). Besides these reports, a recent microdialysis study revealed an increase in the extracellular glycine concentration following calcium-dependent high potassium-mediated depolarization in the substancia nigra pars compacta of the rat (Doretto et al., 1994). Blocking either the tricarboxylic cycle with fluorocitrate or the glutamine synthetase activity markedly increased the extracellular level of glycine, suggesting that glycine could be released from astrocytes under specific conditions (Dopico et al., 2006). However, as the experimental conditions (application of hypo-osmotic or high extracellular potassium solutions) used to evoke this kind of neurotransmitter release failed to activate GlyRs expressed by dopaminergic neurons, the functional significance of this putative nonsynaptic glycine release remains to be elucidated in the substancia nigra pars compacta (Mangin et al., 2002).

\section{SYNAPTIC NEUROTRANSMITTER RELEASE AND INTRINSIC FUNCTIONAL PROPERTIES OF POSTSYNAPTIC GIyRS AND GABA $A_{A}$}

Fast release of neurotransmitters within the synaptic cleft induces the synchronous activation of postsynaptic receptors underlying the fast onset of synaptic events. At single release site, the amplitude of synaptic currents will therefore depend on several pre- and postsynaptic factors, such as the number of neurotransmitter molecules released per vesicle (Kruk et al., 1997), the number (Kruk et al., 1997) and the single conductance levels (Robinson and Kawai, 1993) of postsynaptic receptors and the intrinsic receptor activation properties. 


\section{Deactivation}

A common property of postsynaptic GlyRs and $\mathrm{GABA}_{A} \mathrm{Rs}$ is their fast intrinsic kinetics, allowing them to respond to transient neurotransmitter release. The time course of the deactivation phase of glycinergic and GABAergic postsynaptic currents varies from 5 to $50 \mathrm{~ms}$. These values also fit with the deactivation phase of miniature postsynaptic currents, which represent the activation of few postsynaptic receptors in response to the release of a single vesicle. Since glycine and GABA clearance from the synaptic cleft is considerably faster than the deactivation time course of miniature postsynaptic events, the deactivation time course is expected to be mainly governed by intrinsic functional properties of receptor channels. These intrinsic kinetic properties of postsynaptic receptors largely depend on their subunit composition. For example, postsynaptic currents resulting from the activation of $\alpha 1 \beta$ heteromeric GlyRs display a faster decay time constant than those mediated by $\alpha 2 \beta$ heteromeric GlyRs (Takahashi et al., 1992). In case of postsynaptic $G_{A B A} R$, the length of the burst of channel openings varies according to the subtype of GABA $R$ $\alpha$ subunits present within the channel (Gingrich et al., 1995). However, at inhibitory synapses the deactivation time course of postsynaptic currents can be lengthened through activation of peri-synaptic receptors by spillover of glycine (Ahmadi et al., 2003) or GABA (Rossi and Hamann, 1998) from the synaptic cleft. This prolonged deactivation phase then reflects the integrative image of bursts of channel re-openings, which occur before the agonist dissociates from its binding site (Betz, 1990; Unwin, 1993).

\section{Desensitization}

Prolonged application of agonist induces receptor channel desensitization, a state in which the channels remain closed in the continued presence of the agonist. The rates of onset and recovery from desensitization are crucial in the control of size, decay time and frequency of postsynaptic currents (Jones and Westbrook, 1996).

In case of postsynaptic GlyRs, $\alpha \beta$ heteromeric receptors display slow desensitization kinetics (Legendre, 2001). It is therefore unlikely that receptor desensitization kinetics influence the deactivation time course of glycinergic postsynaptic currents (Legendre, 1998, 2001). However, a recent study has shown that GlyR desensitization can influence the amplitude of glycinergic synaptic currents at stimulation rates $>1 \mathrm{~Hz}$ (Rigo and Legendre, 2006). This finding highlights the first evidence that GlyR desensitization might influence glycinergic synaptic function. Two recent modeling studies that incorporated desensitized states into GlyR kinetic schemes concluded that desensitized states can be reached from both single- and double-bound ligand open states (Gentet and Clements, 2002; Rigo and Legendre, 2006). Interestingly, the phosphorylation of $\alpha 1$-containing GlyRs controls its desensitization level (Gentet and Clements, 2002; Webb and Lynch, 2007), suggesting that synaptic strength can be modified by the activation of metabotropic receptors (Legendre, 2001).

Fast desensitization kinetics of specific postsynaptic $\mathrm{GABA}_{A} \mathrm{R}$ subtypes can shape the deactivation time course of postsynaptic currents. When the rates of onset and recovery from desensitization are fast enough, the receptors enter in a desensitized state during its transitory activation evoked by synaptic vesicular release (Scanziani, 2000). Considering that $\mathrm{GABA}_{A} \mathrm{Rs}$ with pronounced desensitization kinetics have functional significance only when these receptors are located postsynaptically, their desensitization properties could promote negative crosstalk during GABA spillover, between GABAergic synapses and/or between synaptic and non-synaptic GABA release. Although $\mathrm{GABA}_{A} \mathrm{R}$ accumulation in fast desensitized states reduces the amplitude of subsequent inhibitory synaptic currents, slow desensitization is likely to confer a high-pass character in the spatial domain since GABA can diffuse between inhibitory synapses to activate postsynaptic (Ahmadi et al., 2003) or extrasynaptic GABA $A_{A} R$ (Scanziani, 2000). Indeed, GABA reaching distant sites during its spillover, in addition to its small and slowly-rising non-synaptic release (Barbour and Häusser, 1997; Bergles et al., 1999; Rusakov and
Kullmann, 1998), will result predominantly in slow desensitization, rather than activation, of $\mathrm{GABA}_{A} \mathrm{Rs}$ at neighboring synapses (Overstreet et al., 2000). This will therefore reduce the efficiency of neighboring GABAergic synapses during sustained presynaptic activity.

\section{CROSS-TALK BETWEEN GIyRs AND GABA ${ }_{A}$ Rs}

Several recent reports indicate that simultaneous activation of distinct co-aggregated receptors can induce cross-modulation of their respective activation properties. "Cross-talk" mediated by direct or indirect structural interactions between receptors might represent a fast adaptive process involved in the control of synaptic transmission efficacy. A direct "cross-talk" involving protein-protein interactions was demonstrated for several couples of metabotropic and ionotropic receptors, such as D1-dopamine and A1-adenosine receptors (Ginés et al., 2000), D1-dopamine and NMDARs (Lee et al., 2002), D2-dopamine and AMPA receptors (Zou et al., 2005) and D5-dopamine and GABA Rs (Liu et al., 2000). "Cross-talk" also exists between ionotropic receptors, as demonstrated for ATP-P2X2 and $\alpha 3 / \beta 4$ nicotinic receptors (Khakh et al., 2000), ATP-P2X2 and GABA Rs (Sokolova et al., 2001) and ATP-P2X3 and $\mathrm{GABA}_{A} \mathrm{Rs}$ (Toulmé et al., 2007). The cross-modulation of functional receptor properties can be directly mediated through a molecular interaction between receptors. ATP-P2X2/GABA ${ }_{A}$ Rs and ATP-P2X3/GABA $A_{A}$ Rs "crosstalk" involves a direct interaction between the C-terminal domain of the P2X2 subunit and the intracellular loop of the GABA $_{A} R$ B3 subunit (BouéGrabot et al., 2004), or an intracellular QST (386-388) motif in the P2X3 subunit (Toulmé et al., 2007), respectively. Cross-modulation can also be indirect, as described for ATP-P2X2 and nicotinic receptors which require CAMKIl activation (Díaz-Hernández et al., 2006).

\section{Functional interaction between GlyRs and $\mathrm{GABA}_{A} \mathrm{Rs}$}

The idea of a functional interaction between GlyRs and $G_{A B A}$ Rs has been proposed more than 20 years ago (Barker and McBurney, 1979). In spinal cord cell culture, sequential application of glycine and GABA induces a decrease in the amplitude of glycinergic or GABAergic-evoked responses, suggesting that glycine and GABA could share the same conductance channel (Barker and McBurney, 1979). However, this hypothesis has been challenged by the complete cloning of both GlyRs and $\mathrm{GABA}_{A} \mathrm{Rs}$, which shows that these receptors are separate entities. In 1992, Grassi and colleagues demonstrated that cross-inhibitory effects observed in cultured rat hippocampal neurons were due to alterations in the chloride gradient and therefore in the driving force of chloride ions (Grassi, 1992). Since these neurons displayed no evidence for GlyR-GABA $R$ co-aggregation, a direct functional cross-interaction between these receptors was concluded to be unlikely.

The demonstration that cross-inhibition between glycinergic- and GABAergic-evoked responses does not simply result from a shift in the equilibrium potential of chloride ions was provided by Trombley and co-workers (1999). The authors clearly showed that inhibition of the GABAergic response in rat olfactory bulb neurons by pre-application of glycine was voltage-independent and can not be related to a change in the reversal potential of the evoked current. Interestingly, they also observed that this cross-inhibition was asymmetrical, with the glycinergic-evoked response being more efficient to inhibit the GABAergic current than vice-versa. Finally, it has been suggested that this "crosstalk" could be cell type-specific since it was not observed in all cells analyzed (Trombley et al., 1999). As relatively high concentrations of glycine and GABA $(\sim 1 \mathrm{mM})$ were used in this study, it was proposed that cross-inhibition mostly reflects the activation of specific inhibitory amino acid receptors that could equally bind glycine and GABA. A similar conclusion was obtained by Baev and co-workers (1992) from isolated lamprey spinal cord neurons. However, the existence of such a receptor remains to be determined. Moreover, GlyRs and $\mathrm{GABA}_{A} \mathrm{Rs}$ respectively displayed high and specific affinity for their respective endogenous agonist, glycine 
and GABA. Although homomeric $\alpha 1$ and $\alpha 2$ GlyRs could be activated by GABA, this activation required high neurotransmitter concentrations, strongly above the physiological range (De Saint Jan et al., 2001), and there was no evidence for $\mathrm{GABA}_{\mathrm{A}} \mathrm{R}$ activation by glycine.

An asymmetric cross-talk between glycinergic and GABAergic responses mediated by distinct GlyRs and $\mathrm{GABA}_{A}$ Rs has been finally demonstrated on freshly dissociated dorsal horn neurons of juvenile rat spinal cords using the whole-cell patch-clamp recording technique (Li et al., 2003). First, the amplitude of inhibitory currents induced by simultaneous application of glycine and GABA was smaller than the sum of those mediated by separate applications of both neurotransmitters, clearly indicating a cross-modulation of glycine- and GABA-evoked responses. Then, sequential application of glycine and GABA revealed that the GABAevoked current was more affected by glycine pre-application than was the glycinergic one by pre-application of GABA. GlyR activation notably decreases the amplitude and accelerates the rate of desensitization of GABA-evoked currents. This cross-inhibition does not result from a shift in the chloride equilibrium potential and is specifically mediated by GlyRs. Indeed, it was still observed at low glycine concentration $(30 \mu \mathrm{M})$ and could be prevented by the application of the GlyR antagonist strychnine, without affecting GABA-evoked response. These data rule out the existence of a single inhibitory amino acid receptor sensitive to both glycine and GABA, at least in dorsal horn neurons (Li et al., 2003). In these neurons, recovery from cross-inhibition is slow and displays a half-life ranging from 30 to 40 seconds for GlyR-dependent inhibition of GABAevoked response, and a two-time shorter half-life for $\mathrm{GABA}_{A} \mathrm{R}$-dependent inhibition of glycine-evoked response.

Several mechanisms are thought to be involved in this asymmetrical inhibitory cross-modulation, including different intracellular signaling pathways and probably direct protein-protein interactions between GlyRs and $\mathrm{GABA}_{A} \mathrm{Rs}$. GlyR-dependent inhibition of GABA-evoked responses is mediated by dephosphorylation of $\mathrm{GABA}_{\mathrm{A}}$ Rs by the phosphatase $2 \mathrm{~B}$, also known as calcineurin. Indeed, this cross-modulation was prevented by CSPN, a specific calcineurin inhibitor. As a control, application of okadaic acid, which specifically blocks phosphatases 1 and $2 A$, had no effect (Li et al., 2003). Accordingly and since it was irreversible in presence of the kinase inhibitor staurosporine, recovery from cross-modulation is likely to involve $G A B A_{A} R$ re-phosphorylation. Because a direct activation of phosphatase $2 \mathrm{~B}$ through GlyRs awaits experimental confirmation, it is still unclear whether GlyR activation results in direct dephosphorylation of $\mathrm{GABA}_{\mathrm{A}} \mathrm{Rs}$ or whether this is a consequence of dephosphorylation of $\mathrm{GABA}_{A} \mathrm{R}$-associated subsynaptic proteins. Accordingly, Li and co-workers (2003) showed that the increase in intracellular calcium concentration induced by co-application of glycine and GABA was unlikely to activate this phosphatase. Instead, it was proposed that GlyR activation induces a change in the $\mathrm{GABA}_{\mathrm{A}} \mathrm{R}$ conformation through receptor-receptor interaction, resulting in the exposure of phosphorylated $G A B A_{A} R$ sites to phosphatase $2 \mathrm{~B}$. Accordingly, phosphatase $2 \mathrm{~B}$ was shown to be mostly associated with the plasma membrane (Yakel, 1997), suggesting its close association with GABA Rs (Jones and Westbrook, 1997). Moreover, it was found to modulate $\mathrm{GABA}_{\mathrm{A}} \mathrm{R}$ desensitization (Li et al., 2003; Martina et al., 1996).

In contrast to GlyR-dependent inhibition of GABA-evoked responses, $\mathrm{GABA}_{A} \mathrm{R}$-dependent inhibition of glycine-evoked currents does not involve phosphorylation mechanisms. Instead, this cross-modulation could be mediated by direct coupling between GlyRs and $\mathrm{GABA}_{\mathrm{A}} \mathrm{Rs}$, although the contribution of an unknown signaling protein mediating this interaction could not be excluded.

\section{Cross-talk at mixed inhibitory glycinergic/GABAergic synapses}

During synaptic vesicular release, postsynaptic GlyRs and $G_{A B A} R$ R are specifically activated by glycine and GABA, respectively. Although glycinergic and GABAergic neurotransmissions could both contribute to inhibition in several CNS areas, it was assumed for decades that inhibitory synapses were purely glycinergic or purely GABAergic and functioned through distinct pathways. In 1998, the pioneer work of Jonas and co-workers (1998) elegantly demonstrated that, in rat ventral spinal cord, GABA and glycine can be co-released from the same presynaptic terminal to co-activate postsynaptic GlyRs and $\mathrm{GABA}_{A}$ Rs. Functional mixed inhibitory synapses were further identified from interneurons of distinct spinal cord layers (Geiman et al., 2002; González-Forero and Alvarez, 2005; Keller et al., 2001), from neurons of the trapezoid body (Awatramani et al., 2005; Smith et al., 2000), the abducens nucleus (Russier et al., 2002) or the lateral superior olive (Nabekura et al., 2004), as well as from motoneurons of the hypoglossal nucleus (Muller et al., 2006; 0'Brien and Berger, 1999, 2001).

The possibility that mixed glycinergic/GABAergic synapses could represent an immature form of inhibitory synapses remains controversial since their detection at different developmental stages largely depends on the brain area studied. While mixed inhibitory events are recorded at an intermediate stage of synaptic maturation in the trapezoid body (Awatramani et al., 2005), the lateral superior olive (Nabekura et al., 2004), the lamina 1 and lamina 2 of the dorsal spinal cord (Keller et al., 2001) and motoneurons of the hypoglossal nucleus (Muller et al., 2006), they are still detected in Renshaw cells and several distinct interneurons in the spinal cord of mature animals (Geiman et al., 2002; GonzálezForero and Alvarez, 2005). Functional mixed inhibitory synapses were also detected during the whole postnatal development of rat abducens motoneurons (Russier et al., 2002). While mixed inhibitory events can still be detected at mature stages, a developmental decrease in their contribution to whole inhibition is frequently observed. Interestingly in the hypoglossal nucleus, this developmental decrease has been shown to result from the lost ability of presynaptic terminals to release both neurotransmitters, while GlyRs and $\mathrm{GABA}_{A} \mathrm{Rs}$ remain co-aggregated at postsynaptic loci (Muller et al., 2006).

Co-aggregation of GlyRs and $\mathrm{GABA}_{A} \mathrm{Rs}$ at postsynaptic densities of mixed inhibitory synapses suggests that "cross-talk" between GlyRs and $\mathrm{GABA}_{\mathrm{A}}$ Rs could plays a crucial role at these synapses. The occurrence of a possible asymmetrical inhibitory cross-talk at mixed synapses has recently been described in neurons of lamina II of rat spinal cord slices (Mitchell et al., 2007). In these cells, the mean peak amplitude of mixed miniature inhibitory postsynaptic currents was lower than the sum of individual GABAergic and glycinergic synaptic components, and only slightly higher than the averaged amplitude of pure glycinergic synaptic events (Mitchell et al., 2007). The cross-inhibition of glycinergic and GABAergic inhibitory transmissions could also have profound functional implications during neuronal development. In immature animals, glycinergic and GABAergic synaptic activities are depolarizing. Since mixed inhibitory synapses highly contribute to inhibition at these developmental stages, it has been proposed that co-release of glycine and GABA results in a more efficient depolarization and a higher calcium influx in postsynaptic cells (Russier et al., 2002). Indeed, fast glycinergic currents tend to charge the cell capacitance and in turn enhance the strength of the slow GABA component (Russier et al., 2002). In this case, a cross-inhibition will represent an alternative way of limiting excessive depolarization at mixed synapses. In addition to its effect on the amplitude of synaptic events, GlyR activation would decrease the time course of GABAergic postsynaptic currents by speeding up GABA $_{A} R$ desensitization kinetics.

\section{EXTRASYNAPTIC GIyRs AND GABA ${ }_{A}$ : A FUNCTIONAL ADAPTATION}

GlyRs and $\mathrm{GABA}_{A}$ Rs that cannot accumulate at postsynaptic sites display different intrinsic functional properties than postsynaptic ones. This is mainly due to the difference in their activation mode. Indeed, extrasynaptic receptors involved in tonic neurotransmission are slowly activated by spillover and/or non-synaptic release of neurotransmitters and therefore necessitate ongoing activation for a long time.

GlyRs are stabilized at postsynaptic densities through binding of their $\beta$ subunit to the anchoring protein gephyrin. Thus, homomeric $\alpha$ GlyRs 
are expected to be mainly extrasynaptically located. $\alpha 2$ homomeric receptors represent the immature form of GlyRs expressed at embryonic stages, before the onset of $\beta$ subunit expression and the subsequent formation of heteromeric $\alpha \beta$ receptors. These receptors are believed to be involved in cell-to-cell interaction, neuronal differentiation and synaptogenesis (Nguyen et al., 2001). Interestingly, homomeric $\alpha$ GlyRs composed of the $\alpha 2 \mathrm{~A}$ subunit display biophysical properties which strongly differ from those of GlyRs composed of $\alpha 1, \alpha 2 \mathrm{~B}$ or $\alpha 3$ subunits with or without the $\beta$ subunit (Miller et al., 2004). $\alpha 2 \mathrm{~A}$ homomeric GlyRs display very slow kinetics which are not compatible with fast synaptic activation by transitory vesicular release of glycine (Mangin et al., 2003). Indeed, $\alpha 2 \mathrm{~A}$ homomeric GlyRs open only when their glycine binding site is fully occupied and their slow activation rate results from desensitization states linked to bound close states (Mangin et al., 2003). Moreover, their slow closed rate constant, fast opening rate constant and slow deactivation rate strongly suggest that these receptors are well adapted to non-synaptic release of glycine (Mangin et al., 2003). Finally, $\alpha 2 A$ homomeric GlyRs display slower and smaller desensitization kinetics when compared to postsynaptic GlyRs, allowing them to remain functional in the continuous presence of glycine.

Another major functional specificity of $\alpha 2 \mathrm{~A}$ homomeric GlyRs is its ten times lower apparent affinity for glycine than other GlyR subtypes. Consequently, these receptors necessitate a glycine concentration $\geq 10 \mu \mathrm{M}$ to be activated (Mangin et al., 2003). This concentration limit might act as a high pass filter to prevent unspecific GlyR activation by a high level of glycine in the extracellular space. This mechanism might serve notably in the developing CNS in which glycine re-uptake transporters are not fully active (Wall and Usowicz, 1997).

Homomeric $\alpha 2 A$ GlyR is probably not the only GlyR subtype displaying functional properties adapted to non-synaptic release of glycine. Recently, a new isoform of the $\alpha 3$ GlyR subunit resulting from cystidine 554 deamination (RNA editing) has been identified (Meier et al., 2005). The subsequent substitution of a proline by a leucine at position 185 confers high glycine sensitivity to this receptor (submicromolar concentration), thereby promoting the generation of sustained chloride conductances associated with tonic inhibition. Interestingly, the level of GlyR $\alpha 3$ subunit C554U RNA editing has been shown to be enhanced in response to brain lesion, indicating that the conditional regulation of GlyR $\alpha 3$ subunit P185L is likely to be part of a post-transcriptional adaptive mechanism in neurons.

Also in case of $\mathrm{GABA}_{A} \mathrm{Rs}$, extrasynaptic $\delta$-containing receptors $(\alpha \beta \delta)$ show a higher efficiency (lower $\mathrm{EC}_{50}$ ) and desensitize more slowly and less extensively than postsynaptic $\alpha \beta \gamma \mathrm{GABA}_{A} \mathrm{Rs}$ (Stórustovu and Ebert, 2006). Another example is given by $\alpha 5$-containing extrasynaptic $G_{A B A_{A}} R s$ that display a reduction in their desensitization kinetics when compared with GABA Rs containing other $\alpha$ subunits (Gingrich et al., 1995). Since extrasynaptic GABA $A_{A}$ s desensitize slowly and incompletely, they remain functional when exposed to a continuous presence of their agonist within the extracellular space, as well as during spillover or non-synaptic release of GABA.

\section{IS THE LATERAL DIFFUSION OF GlyRs AND GABA ${ }_{A}$ Rs FROM AND TO THE SYNAPTIC CLEFT ASSOCIATED WITH CHANGES IN THEIR FUNCTIONAL PROPERTIES?}

Recent reports clearly establish the dynamic feature of receptor accumulation at postsynaptic sites and, especially, their lateral diffusion from and to the postsynaptic loci. The fact that receptor trapping by the anchoring protein is fast and reversible implies that the density of receptors within a synaptic cluster depends on the dynamic equilibrium between the pools of receptors trapped at postsynaptic loci and those diffusing out of the synapse. The lateral diffusion of receptors in the plasma membrane has been well established in case of highly mobile acetylcholine receptors in developing neuromuscular synapses (Burden, 1998). This mechanism has been recently described for AMPARs and NMDARs at excitatory synapses (Borgdorff and Choquet, 2002; Groc et al., 2004), as well as for GlyRs and $\mathrm{GABA}_{\mathrm{A}} \mathrm{Rs}$ at inhibitory synapses (Dahan et al., 2003). Lateral diffusion of receptors implies that they can oscillate between postsynaptic and extrasynaptic sites. Accordingly, they will be differentially activated depending on their subcellular distribution. Indeed, they will be phasically activated at postsynaptic sites and tonically activated at extrasynaptic sites.

\section{GlyR aggregation and functional properties}

Postsynaptic and extrasynaptic receptors have different intrinsic functional properties (see above). Since postsynaptic receptors display fast desensitization properties, which are not compatible with tonic activation, the functional significance of their lateral diffusion to extrasynaptic sites is questionable unless one considers that these properties could change with the subcellular receptor localization. Interestingly, the functional receptor properties were shown to change according to their aggregation level, which tends to be higher at postsynaptic densities than at extrasynaptic sites.

Using heterologous expression of the human GlyR $\alpha 1$ subunit, Taleb and Betz demonstrated that functional properties of $\alpha 1$-containing GlyRs depend on their density at the cellular membrane (Taleb and Betz, 1994). The injection of the GlyR $\alpha 1$ subunit cDNA into Xenopus oocyte induced the expression of homomeric $\alpha 1$ GlyRs over a wide membranous density range. The GlyR density was estimated by measuring the maximum amplitude of glycinergic currents evoked by the application of a saturating glycine concentration. A significant change in GlyR pharmacology could be correlated with different GlyR density levels. When highly concentrated at the oocyte membrane, GlyRs displayed $\mathrm{a} \approx 5$-fold lower $\mathrm{EC}_{50}$ value for glycine, $\beta$-alanine and taurine than poorly aggregated receptors (Taleb and Betz, 1994). Highly concentrated receptors were also more resistant to strychnine antagonism. The authors proposed that increasing the density of GlyRs might increase the receptor affinity for its agonists. However, a change in $\mathrm{EC}_{50}$ value does not necessarily imply a change in receptor affinity. $\mathrm{EC}_{50}$, or apparent affinity, reflects both ligand binding and conformational changes leading to channel opening. This parameter depends on the agonist microscopic dissociation constant $K_{\mathrm{A}}\left(K_{\mathrm{A}}=K_{\text {off }} / K_{\text {on }}\right.$, where $k_{\text {off }}$ is the dissociation rate constant in second ${ }^{-1}$ and $k_{\text {on }}$ is the association rate constant in $\mathrm{M}^{-1}$ second ${ }^{-1}$ ) and the open/close isomerization equilibrium constant or efficacy $E(E=\beta / \alpha$ where $\beta$ is the opening rate constant and $\alpha$ the closing rate constant). $\mathrm{EC}_{50}$ can be estimated when $=K_{\mathrm{A}} /(1+E)$. Interestingly, the value of the $\mathrm{EC}_{50}$ can change independently of $E$ or $K_{\mathrm{A}}$ (Colquhoun, 1998; Legendre, 2001). Other parameters, such as desensitization kinetics, might also influence $\mathrm{EC}_{50}$.

A functional significance of this phenomenon has been recently proposed in a study combining fast flow application techniques and outsideout patch clamp single channel recordings from cultured transfected human embryonic kidney (HEK) 293 cells expressing a chimer form of the GlyR $\alpha 1$ subunit (Legendre et al., 2002). Fast flow application technique allows solution exchange in the vicinity of an outside-out patch in less than $0.1 \mathrm{~ms}$ and provides a direct estimation of receptor conformational changes over time. Legendre and co-workers (2002) compared the impact of GlyR density on their kinetics when GlyR expression was globally increased in HEK cell membranes or when local GlyR aggregation was induced by gephyrin co-transfection. Gephyrin interacts with the $\beta$ GlyR subunit, implying the study of aggregated heteromeric $\alpha \beta$ GlyRs. However, it is not possible to obtain a pure population of $\alpha \beta$ GlyRs in HEK cells co-transfected with $\alpha$ and $\beta$ subunits. To overcome this problem, the authors used a chimeric GlyR $\alpha 1$ subunit $\left(\alpha 1 \beta_{\mathrm{gb}}\right)$ bearing the gephyrin-binding site in its TM3-TM4 intracellular loop. As previously observed (Taleb and Betz, 1994), Legendre and co-workers described changes in GlyR functional properties depending on their aggregation level. However, in contrast to what was previously reported, they showed that increasing an GlyR aggregation level involved a parallel increase in GlyR desensitization without affecting the apparent affinity. Since fast 
flow techniques allow the study of fast changes in receptor kinetics, they further showed that the changes in $\mathrm{EC}_{50}$ previously observed were directly related to changes in receptors desensitization kinetics. Finally, since the large TM3-TM4 intracellular domain of the GlyR $\alpha 1$ subunit can interact with its TM1-TM2 intracellular loop (Nikolic et al., 1998), it has been hypothesized that changes in desensitization properties with higher receptor density could arise from a higher level of intracellular interactions. Thus, gephyrin binding to $\alpha 1 \beta_{\mathrm{gb}}$ subunit could change the conformation of the GlyR TM3-TM4 intracellular loop and modify its interaction with the TM1-TM2 intracellular domain, mimicking a higher GlyR density. It is noteworthy that $\alpha 1 \beta_{\text {ob }}$-containing GlyRs expressed at high level in HEK cells display desensitization kinetics which are considerably faster than those described for $\alpha 1 \beta$ GlyRs expressed in neurons. However, insertion of the $\beta_{\mathrm{ab}}$ sequence into the TM3-TM4 intracellular loop of the GlyR $\alpha 1$ subunit is unlikely to account for these difference since desensitization kinetics of $\alpha 1$ - and $\alpha 1 \beta_{\mathrm{gb}}$-containing GlyRs were similar (Legendre et al., 2002).

As an adaptative mechanism of neurotransmission, the lateral diffusion of GlyRs might therefore have important functional consequences. For example, in case of sustained presynaptic activity, extrasynaptic slightly desensitizing GlyRs will be continuously activated by glycine spillover and in turn enhance inhibitory synaptic strength.

\section{GlyR aggregation and gephyrin}

GlyRs form clusters when binding to gephyrin or become diffuse when they dissociate from it (Meier and Grantyn, 2004; Meier et al., 2000). A similar mechanism could occur in neurons under physiological conditions. However, since synaptic gephyrin clusters also display a fast dynamic behavior (Hanus et al., 2006), GlyRs diffusing out of the synaptic cleft would not necessarily dissociate from gephyrin. If so, extrasynaptic GlyRs would remain aggregated and conserve similar desensitization kinetics than postsynaptic receptors. Accordingly, such extrasynaptic receptors would be poorly efficient in response to a slow release of glycine. But, GlyR diffusion and lateral motion of gephyrin clusters are two distinct dynamic processes occurring within the postsynaptic density, with gephyrin clusters moving on longer time scales (Hanus et al., 2006). The decreased diffusion of GlyRs at postsynaptic loci reflects their "confinement" by postsynaptic scaffold proteins (Choquet and Triller, 2003), arguing in favor of a binding-unbinding postsynaptic mechanism between GlyRs and gephyrin. This hypothesis is supported by the remaining presence of GlyRs in membranes of neurons in which gephyrin expression is impaired (Kirsch et al., 1993; Kneussel et al., 1999). Accordingly, Charrier and co-workers (2006) recently demonstrated that synaptic expression and maintenance of GlyRs and gephyrin are controlled by distinct mechanisms involving cytoskeleton dynamics. GlyR and gephyrin were tagged with different fluorophores and co-transfected in cultured spinal cord neurons. During cytoskeleton depolymerization, GlyR-associated fluorescence was shown to decrease before the gephyrin-associated one, therefore suggesting that receptor exchanges between synaptic and extrasynaptic sites do not reflect an increased mobility of the GlyRgephyrin complex only (Charrier et al., 2006).

\section{GABA $_{A} R$ aggregation and functional properties}

Similarly to GlyRs, $G_{A B A}$ Rs display lateral mobility and exchange between postsynaptic and extrasynaptic sites (Jacob et al., 2005). Therefore, it is not surprising that the $\mathrm{GABA}_{A} \mathrm{R}$ functional properties also depend on their aggregation level. The functional consequence of this dependency has been analyzed in cultured hippocampal neurons using fast flow application techniques and patch clamp outside-out single channel recordings (Petrini et al., 2003). GABA $A_{A}$ aggregation is dramatically reduced under microtubule disruption (Kneussel and Betz, 2000; Petrini et al., 2003). Contrary to what was observed for GlyRs, a decrease in $\mathrm{GABA}_{A} \mathrm{R}$ aggregation in response to microtubule depolymerization by nocodazole resulted in increased $G A B A_{A} R$ desensitization kinetics. Indeed, the rise time of GABA-evoked currents and the onset of desensitization were faster
(Petrini et al., 2003). These observations were coherent with a previous report showing that GABARAP-induced aggregation of GABA ${ }_{A}$ Rs induces faster deactivation and slower desensitization when compared to diffuse receptors (Chen et al., 2000). GABA ${ }_{A}$ Rs displaying fast desensitization kinetics are expected to be poorly efficient in response to a continuous presence of GABA (Jones and Westbrook, 1995; Scanziani, 2000). This suggests that, in contrast with GlyRs, GABA Rs moving to extrasynaptic sites through lateral diffusion would not be functional anymore.

\section{PERSPECTIVES}

Inhibitory neurotransmission is subject to continuous and complex readjustments. Recently acquired knowledge and ongoing investigations are uncovering mechanisms that specify the role and the contribution of extrasynaptic and postsynaptic GlyRs and $\mathrm{GABA}_{\mathrm{A}} \mathrm{Rs}$ to inhibition, as well as their functional adaptation during lateral mobility. Although the functional properties of extrasynaptic GlyRs and $\mathrm{GABA}_{\mathrm{A}} \mathrm{Rs}$ have been extensively studied, the mechanisms underlying non-synaptic release of glycine and GABA are still poorly understood. So far, only non-synaptic release of taurine has been described to activate GlyRs in the developing cortex (Flint et al., 1998) and in the neurohypophysis of the adult rat (Hussy et al., 2001). GlyRs and $G_{A B A}$ Rs are widely expressed in the developing CNS, at both postsynaptic and extrasynaptic loci. Impairment in their expression strongly alters neuronal developmental processes. Thus, it is of crucial importance to determine the origin and release mechanism of neurotransmitters, which activate these receptors during synaptogenesis.

Another challenge is to investigate the molecular mechanisms underlying changes in the functional properties of GlyRs and $G A B A_{A} R s$, depending on their aggregation level. This would be particularly relevant in case of mixed inhibitory synapses, where GlyRs and $\mathrm{GABA}_{A}$ Rs c0-aggregate at postsynaptic densities and cross-modulate their activity. Moreover, although a direct crosstalk between GlyRs and $\mathrm{GABA}_{\mathrm{A}} \mathrm{Rs}$ has now been demonstrated, the molecular pathway and the physiological role of this mechanism remain to be clearly determined.

\section{CONFLICT OF INTEREST STATEMENT}

The authors declare that this research was conducted in the absence of any commercial or financial relationships that could be construed as a potential conflict of interest.

\section{ACKNOWLEDGEMENT}

This work was supported by AFM (Association Française contre les Myopathies), FRC (federation pour la recherche sur le cerveau), INSERM and CNRS.

\section{REFERENCES}

Ahmadi, S., Muth-Selbach, U., Lauterbach, A., Lipfert, P., Neuhuber, W. L., and Zeilhofer, H. U. (2003). Facilitation of spinal NMDA receptor currents by spillover of synaptically released glycine. Science 300, 2094-2097.

Attwell, D., Barbour, B., and Szatkowski, M. (1993). Nonvesicular release of neurotransmitter. Neuron 11, 401-407.

Auger, C., and Marty, A. (1997). Heterogeneity of functional synaptic parameters among single release sites. Neuron 19, 139-150.

Awatramani, G. B., Turecek, R., and Trussell, L. 0. (2005). Staggered development of GABAergic and glycinergic transmission in the MNTB. J. Neurophysiol. 93, 819-828.

Baev, K. V., Rusin, K. I., and Safronov, B. V. (1992). Primary receptor for inhibitory transmitters in lamprey spinal cord neurons. Neuroscience 46, 931-941.

Barberis, A., Petrini, E. M., and Cherubini, E. (2004). Presynaptic source of quantal size variability at GABAergic synapses in rat hippocampal neurons in culture. Eur. J. Neurosci. 20, 1803-1810.

Barbour, B., and Häusser, M. (1997). Intersynaptic diffusion of neurotransmitter. Trends Neurosci. 20, 377-384.

Barker, J. L., and McBurney, R. N. (1979). GABA and glycine may share the same conductance channel on cultured mammalian neurones. Nature 277, 234-236.

Bergles, D. E., Diamond, J. S., and Jahr, C. E. (1999). Clearance of glutamate inside the synapse and beyond. Curr. Opin. Neurobiol. 9, 293-298. 
Betz, H. (1990). Ligand-gated ion channels in the brain: the amino acid receptor superfamily. Neuron 5, 383-392.

Bieda, M. C., and Maclver, M. B. (2004). Major role for tonic GABAA conductances in anesthetic suppression of intrinsic neuronal excitability. J. Neurophysiol. 92, 1658-1667.

Borgdorff, A. J., and Choquet, D. (2002). Regulation of AMPA receptor lateral movements. Nature 417, 649-653.

Boué-Grabot, E., Toulmé, E., Emerit, M. B., and Garret, M. (2004). Subunit-specific coupling between gamma-aminobutyric acid type $A$ and $P 2 X 2$ receptor channels. J. Biol. Chem. 279, 52517-52525.

Brickley, S. G., Cull-Candy, S. G., and Farrant, M. (1996). Development of a tonic form of synaptic inhibition in rat cerebellar granule cells resulting from persistent activation of GABAA receptors. J. Physiol. 497, 753-759.

Bruneau, E. G., and Akaaboune, M. (2006). Running to stand still: ionotropic receptor dynamics at central and peripheral synapses. Mol. Neurobiol. 34, 137-151.

Brünig, I., Scotti, E., Sidler, C., and Fritschy, J. M. (2002). Intact sorting, targeting, and clustering of gamma-aminobutyric acid A receptor subtypes in hippocampal neurons in vitro. J. Comp. Neurol. 443, 43-55.

Burden, S. J. (1998). The formation of neuromuscular synapses. Genes Dev. 12 , 133-148.

Carta, M., Mameli, M., and Valenzuela, C. F. (2004). Alcohol enhances GABAergic transmission to cerebellar granule cells via an increase in Golgi cell excitability. J. Neurosci. 24, 3746-3751.

Charrier, C., Ehrensperger, M. V., Dahan, M., Lévi, S., and Triller, A. (2006). Cytoskeleton regulation of glycine receptor number at synapses and diffusion in the plasma membrane. J. Neurosci. 26, 8502-8511.

Chen, L., Wang, H., Vicini, S., and Olsen, R. W. (2000). The gamma-aminobutyric acid type $\mathrm{A}$ (GABAA) receptor-associated protein (GABARAP) promotes GABAA receptor clustering and modulates the channel kinetics. Proc. Natl. Acad. Sci. U.S.A. 97 11557-11562.

Choquet, D., and Triller, A. (2003). The role of receptor diffusion in the organization of the postsynaptic membrane. Nat. Rev. Neurosci. 4, 251-265.

Colquhoun, D. (1998). Binding, gating, affinity and efficacy: the interpretation of structureactivity relationships for agonists and of the effects of mutating receptors. $\mathrm{Br}$. J. Pharmacol. 125, 924-947.

Cope, D. W., Hughes, S. W., and Crunelli, V. (2005). GABAA receptor-mediated tonic inhibition in thalamic neurons. J. Neurosci. 25, 11553-11563.

Crestani, F., Keist, R., Fritschy, J. M., Benke, D., Vogt, K., Prut, L., Blüthmann, H., Möhler, H. and Rudolph, U. (2002). Trace fear conditioning involves hippocampal alpha5 GABA(A) receptors. Proc. Natl. Acad. Sci. U.S.A. 99, 8980-8985.

Dahan, M., Lévi, S., Luccardini, C., Rostaing, P., Riveau, B., and Triller, A. (2003). Diffusion dynamics of glycine receptors revealed by single-quantum dot tracking. Science 302, 442-445.

De Saint Jan, D., David-Watine, B., Korn, H., and Bregestovski, P. (2001). Activation of human alpha1 and alpha2 homomeric glycine receptors by taurine and GABA J. Physiol. 535, 741-755.

Díaz-Hernández, M., Sánchez-Nogueiro, J., and Miras-Portugal, M. T. (2006). Role of CaCMKII in the cross-talk between ionotropic nucleotide and nicotinic receptors in individual cholinergic terminals. J. Mol. Neurosci. 30, 177-180.

Dopico, J. G., González-Hernández, T., Pérez, I. M., García, I. G., Abril, A. M., Inchausti, J. 0. , and Rodríguez-Díaz, M. (2006). Glycine release in the substantia nigra: interaction with glutamate and GABA. Neuropharmacology 50, 548-557.

Doretto, M. C., Burger, R. L., Mishra, P. K., Garcia-Cairasco, N., Dailey, J. W., and Jobe, P. C (1994). A microdialysis study of amino acid concentrations in the extracellular fluid of the substantia nigra of freely behaving GEPR-9s: relationship to seizure predisposition. Epilepsy Res. 17, 157-165.

Dumoulin, A., Rostaing, P., Bedet, C., Lévi, S., Isambert, M. F., Henry, J. P., Triller, A., and Gasnier, B. (1999). Presence of the vesicular inhibitory amino acid transporter in GABAergic and glycinergic synaptic terminal boutons. J. Cell Sci. 112, 811-823.

Dutton, G. R., Barry, M., Simmons, M. L., and Philibert, R. A. (1991). Astrocyte taurine. Ann. N. Y. Acad. Sci. 633, 489-500

Essrich, C., Lorez, M., Benson, J. A., Fritschy, J. M., and Lüscher, B. (1998). Postsynaptic clustering of major GABAA receptor subtypes requires the gamma 2 subunit and gephyrin. Nat. Neurosci. 1, 563-571.

Evanko, D. S., Zhang, Q., Zorec, R., and Haydon, P. G. (2004). Defining pathways of loss and secretion of chemical messengers from astrocytes. Glia 47, 233-240.

Farrant, M., and Nusser, Z. (2005). Variations on an inhibitory theme: phasic and tonic activation of GABA(A) receptors. Nat. Rev. Neurosci. 6, 215-229.

Flint, A. C., Liu, X., and Kriegstein, A. R. (1998). Nonsynaptic glycine receptor activation during early neocortical development. Neuron $20,43-53$.

Fritschy, J. M., Benke, D., Mertens, S., Oertel, W. H., Bachi, T., and Möhler, H. (1992) Five subtypes of type A gamma-aminobutyric acid receptors identified in neurons by double and triple immunofluorescence staining with subunit-specific antibodies. Proc. Natl. Acad. Sci. U.S.A. 89, 6726-6730

Geiman, E. J., Zheng, W., Fritschy, J. M., and Alvarez, F. J. (2002). Glycine and GABA(A) receptor subunits on Renshaw cells: relationship with presynaptic neurotransmitters and postsynaptic gephyrin clusters. J. Comp. Neurol. 444, 275-289.

Gentet, L. J., and Clements, J. D. (2002). Binding site stoichiometry and the effects of phosphorylation on human alpha1 homomeric glycine receptors. J. Physiol. 544 97-106.
Ginés, S., Hillion, J., Torvinen, M., Le Crom, S., Casadó, V., Canela, E. I., Rondin, S. Lew, J. Y., Watson, S., Zoli, M., Agnati, L. F., Verniera, P., Lluis, C., Ferré, S., Fuxe, K., and Franco, R. (2000). Dopamine D1 and adenosine A1 receptors form functionally interacting heteromeric complexes. Proc. Natl. Acad. Sci. U.S.A. 97, 8606-8611.

Gingrich, K. J., Roberts, W. A., and Kass, R. S. (1995). Dependence of the GABAA recepto gating kinetics on the alpha-subunit isoform: implications for structure-function relations and synaptic transmission. J. Physiol. 489, 529-543.

González-Forero, D., and Alvarez, F. J. (2005). Differential postnatal maturation of GABAA glycine receptor, and mixed synaptic currents in Renshaw cells and ventral spinal interneurons. J. Neurosci. 25, 2010-2023.

Grassi, F. (1992). Cl(-)-mediated interaction between GABA and glycine currents in cultured rat hippocampal neurons. Brain Res. 594, 115-123.

Groc, L., Heine, M., Cognet, L., Brickley, K., Stephenson, F. A., Lounis, B., and Choquet, D. (2004). Differential activity-dependent regulation of the lateral mobilities of AMPA and NMDA receptors. Nat. Neurosci. 7, 695-696.

Hanus, C., Ehrensperger, M. V., and Triller, A. (2006). Activity-dependent movements of postsynaptic scaffolds at inhibitory synapses. J. Neurosci. 26, 4586-4595.

Hanus, C., Vannier, C., and Triller, A. (2004). Intracellular association of glycine receptor with gephyrin increases its plasma membrane accumulation rate. J. Neurosci. 24 1119-1128.

Häusser, M. A., Yung, W. H., and Lacey, M. G. (1992). Taurine and glycine activate the same $\mathrm{Cl}^{-}$conductance in substantia nigra dopamine neurons. Brain Res. 571, 103-108.

Heinze, L., Harvey, R. J., Haverkamp, S., and Wässle, H. (2007). Diversity of glycine receptors in the mouse retina: localization of the alpha4 subunit. J. Comp. Neurol. 500, 693-707.

Hussy, N., Brès, V., Rochette, M., Duvoid, A., Alonso, G., Dayanithi, G., and Moos, F. C. (2001). Osmoregulation of vasopressin secretion via activation of neurohypophysia nerve terminals glycine receptors by glial taurine. J. Neurosci. 21, 7110-7116.

Jacob, T. C., Bogdanov, Y. D., Magnus, C., Saliba, R. S., Kittler, J. T., Haydon, P. G., and Moss, S. J. (2005). Gephyrin regulates the cell surface dynamics of synaptic GABAA receptors. J. Neurosci. 25, 10469-10478.

Jensen, K., Chiu, C. S., Sokolova, I., Lester, H. A., and Mody, I. (2003). GABA transporter-1 (GAT1)-deficient mice: differential tonic activation of GABAA versus GABAB receptors in the hippocampus. J. Neurophysiol. 90, 2690-2701.

Jonas, P., Bischofberger, J., and Sandkühler, J. (1998). Corelease of two fast neurotransmitters at a central synapse. Science 281, 419-424.

Jones, M. V., and Westbrook, G. L. (1995). Desensitized states prolong GABAA channe responses to brief agonist pulses. Neuron 15, 181-191.

Jones, M. V., and Westbrook, G. L. (1996). The impact of receptor desensitization on fast synaptic transmission. Trends Neurosci. 19, 96-101.

Jones, M. V., and Westbrook, G. L. (1997). Shaping of IPSCs by endogenous calcineurin activity. J. Neurosci. 17, 7626-7633.

Keller, A. F., Coull, J. A., Chery, N., Poisbeau, P., and De Koninck, Y. (2001). Region-specific developmental specialization of GABA-glycine cosynapses in laminas I-II of the rat spinal dorsal horn. J. Neurosci. 21, 7871-7880.

Khakh, B. S., Zhou, X., Sydes, J., Galligan, J. J., and Lester, H. A. (2000). State-dependent cross-inhibition between transmitter-gated cation channels. Nature 406, 405-410.

Kirsch, J., and Betz, H. (1993). Widespread expression of gephyrin, a putative glycine receptor-tubulin linker protein, in rat brain. Brain Res. 621, 301-310.

Kirsch, J., Wolters, I., Triller, A., and Betz, H. (1993). Gephyrin antisense oligonucleotides prevent glycine receptor clustering in spinal neurons. Nature 366, 745-748.

Kneussel, M., and Betz, H. (2000). Clustering of inhibitory neurotransmitter receptors at developing postsynaptic sites: the membrane activation model. Trends Neurosci. 23, 429-435.

Kneussel, M., Brandstätter, J. H., Laube, B., Stahl, S., Müller, U., and Betz, H. (1999). Loss of postsynaptic GABA(A) receptor clustering in gephyrin-deficient mice. J. Neurosci. 19, 9289-9297.

Kneussel, M., and Loebrich, S. (2007). Trafficking and synaptic anchoring of ionotropic inhibitory neurotransmitter receptors. Biol. Cell. 99, 297-309.

Kruk, P. J., Korn, H., and Faber, D. S. (1997). The effects of geometrical parameters on synaptic transmission: a Monte Carlo simulation study. Biophys. J. 73, 2874-2890.

Kuhse, J., Kuryatov, A., Maulet, Y., Malosio, M. L., Schmieden, V., and Betz, H. (1991) Alternative splicing generates two isoforms of the alpha 2 subunit of the inhibitory glycine receptor. FEBS Lett. 283, 73-77.

Lee, F. J., Xue, S., Pei, L., Vukusic, B., Chéry, N., Wang, Y., Wang, Y. T., Niznik, H. B., $\mathrm{Yu}, \mathrm{X} . \mathrm{M}$., and Liu, F. (2002). Dual regulation of NMDA receptor functions by direct protein-protein interactions with the dopamine D1 receptor. Cell 111, 219-230.

Legendre, P. (1997). Pharmacological evidence for two types of postsynaptic glycinergic receptors on the Mauthner cell of 52-h-old zebrafish larvae. J. Neurophysiol. 77 $2400-2415$

Legendre, P. (1998). A reluctant gating mode of glycine receptor channels determines the time course of inhibitory miniature synaptic events in zebrafish hindbrain neurons. J. Neurosci. 18, 2856-2870.

Legendre, P. (2001). The glycinergic inhibitory synapse. Cell. Mol. Life Sci. 58, 760-793.

Legendre, P., Muller, E., Badiu, C. I., Meier, J., Vannier, C., and Triller, A. (2002) Desensitization of homomeric alpha1 glycine receptor increases with receptor density. Mol. Pharmacol. 62, 817-827.

Li, Y., Wu, L. J., Legendre, P., and Xu, T. L. (2003). Asymmetric cross-inhibition between GABAA and glycine receptors in rat spinal dorsal horn neurons. J. Biol. Chem. 378 38637-38645. 
Liu, F., Wan, Q., Pristupa, Z. B., Yu, X. M., Wang, Y. T., and Niznik, H. B. (2000). Direct protein-protein coupling enables cross-talk between dopamine D5 and gammaaminobutyric acid A receptors. Nature 403, 274-280.

LoTurco, J. J., Owens, D. F., Heath, M. J., Davis, M. B., and Kriegstein, A. R. (1995) GABA and glutamate depolarize cortical progenitor cells and inhibit DNA synthesis. Neuron 15, 1287-1298.

Lynch, J. W. (2004). Molecular structure and function of the glycine receptor chloride channel. Physiol. Rev. 84, 1051-1095.

Macdonald, R. L., and Olsen, R. W. (1994). GABAA receptor channels. Annu. Rev. Neurosci. 17, 569-602.

Madsen, S., Ottersen, 0. P., and Storm-Mathisen, J. (1985). Immunocytochemical visualization of taurine: neuronal localization in the rat cerebellum. Neurosci. Lett. 60, 255-260.

Malosio, M. L., Grenningloh, G., Kuhse, J., Schmieden, V., Schmitt, B., Prior, P., and Betz, H. (1991). Alternative splicing generates two variants of the alpha 1 subunit of the inhibitory glycine receptor. J. Biol. Chem. 266, 2048-2053.

Malosio, M. L., Marquèze-Pouey, B., Kuhse, J., and Betz, H. (1991). Widespread expression of glycine receptor subunit mRNAs in the adult and developing rat brain. EMBO J. 10, 2401-2409.

Mangin, J. M., Baloul, M., Prado De Carvalho, L., Rogister, B., Rigo, J. M., and Legendre, P. (2003). Kinetic properties of the alpha2 homo-oligomeric glycine receptor impairs a proper synaptic functioning. J. Physiol. 553, 369-386.

Mangin, J. M., Guyon, A., Eugène, D., Paupardin-Tritsch, D., and Legendre, P. (2002) Functional glycine receptor maturation in the absence of glycinergic input in dopaminergic neurones of the rat substantia nigra. J. Physiol. 542, 685-697.

Marchionni, I., Omrani, A., and Cherubini, E. (2007). In the developing rat hippocampus a tonic GABAA-mediated conductance selectively enhances the glutamatergic drive of principal cells. J. Physiol. 581, 515-528.

Martina, M., Mozrzymas, J. W., Boddeke, H. W., and Cherubini, E. (1996). The calcineurin inhibitor cyclosporin A-cyclophilin A complex reduces desensitization of GABAAmediated responses in acutely dissociated rat hippocampal neurons. Neurosci. Lett. 215, 95-98.

Meier, J., and Grantyn, R. (2004). A gephyrin-related mechanism restraining glycine receptor anchoring at GABAergic synapses. J. Neurosci. 24, 1398-1405.

Meier, J. C., Henneberger, C., Melnick, I., Racca, C., Harvey, R. J., Heinemann, U., Schmieden, V., and Grantyn, R. (2005). RNA editing produces glycine receptor Q3P185L resulting in high agonist potency. Nat. Neurosci. 8, 736-744.

Meier, J., Meunier-Durmort, C., Forest, C., Triller, A., and Vannier, C. (2000). Formation of glycine receptor clusters and their accumulation at synapses. J. Cell Sci. 113, 2783-2795.

Meyer, G., Kirsch, J., Betz, H., and Langosch, D. (1995). Identification of a gephyrin binding motif on the glycine receptor beta subunit. Neuron $15,563-572$.

Miller, P. S., Harvey, R. J., and Smart, T. G. (2004). Differential agonist sensitivity of glycine receptor alpha2 subunit splice variants. Br. J. Pharmacol. 143, 19-26.

Mitchell, E. A., Gentet, L. J., Dempster, J., and Belelli, D. (2007). GABAA and glycine receptor-mediated transmission in rat lamina II neurones: relevance to the analgesic actions of neuroactive steroids. J. Physiol. 583, 1021-1040.

Mohler, H., Knoflach, F., Paysan, J., Motejlek, K., Benke, D., Lüscher, B., and Fritschy, J. M. (1995). Heterogeneity of GABAA-receptors: cell-specific expression, pharmacology, and regulation. Neurochem. Res. 20,631-636.

Mozrzymas, J. W., Barberis, A., Michalak, K., and Cherubini, E. (1999) Chlorpromazine inhibits miniature GABAergic currents by reducing the binding and by increasing the unbinding rate of GABAA receptors. J. Neurosci. 19, 2474-2488.

Muller, E., Le Corronc, H., Triller, A., and Legendre, P., (2006). Developmental dissociation of presynaptic inhibitory neurotransmitter and postsynaptic receptor clustering in the hypoglossal nucleus. Mol. Cell. Neurosci. 32, 254-273.

Nabekura, J., Katsurabayashi, S., Kakazu, Y., Shibata, S., Matsubara, A., Jinno, S. Mizoguchi, Y., Sasaki, A., and Ishibashi, H. (2004). Developmental switch from GABA to glycine release in single central synaptic terminals. Nat. Neurosci. 7, 17-23.

Nguyen, L., Rigo, J. M., Rocher, V., Belachew, S., Malgrange, B., Rogister, B., Leprince, P., and Moonen, G. (2001). Neurotransmitters as early signals for central nervous system development. Cell Tissue Res. 305, 187-202.

Nikolic, Z., Laube, B., Weber, R. G., Lichter, P., Kioschis, P., Poustka, A., Mülhardt, C. and Becker, C. M. (1998). The human glycine receptor subunit alpha3. Glra3 gene structure, chromosomal localization, and functional characterization of alternative transcripts. J. Biol. Chem. 273, 19708-19714.

Nusser, Z., Roberts, J. D., Baude, A., Richards, J. G., and Somogyi, P. (1995). Relative densities of synaptic and extrasynaptic GABAA receptors on cerebellar granule cells as determined by a quantitative immunogold method. J. Neurosci. 15 , 2948-2960.

Nusser, Z., Sieghart, W., and Somogyi, P. (1998). Segregation of different GABAA receptors to synaptic and extrasynaptic membranes of cerebellar granule cells. J. Neurosci. 18, 1693-1703.

O'Brien, J. A., and Berger, A. J. (1999). Cotransmission of GABA and glycine to brain stem motoneurons. J. Neurophysiol. 82, 1638-1641.

0'Brien, J. A., and Berger, A. J. (2001). The nonuniform distribution of the GABA(A) receptor alpha 1 subunit influences inhibitory synaptic transmission to motoneurons within a motor nucleus. J. Neurosci. 21, 8482-8494.

Overstreet, L. S., Jones, M. V., and Westbrook, G. L. (2000). Slow desensitization regulates the availability of synaptic GABA(A) receptors. J. Neurosci. 20, 7914-7921.
Paysan, J., and Fritschy, J. M. (1998) GABAA-receptor subtypes in developing brain. Actors or spectators? Perspect. Dev. Neurobiol. 5, 179-192.

Petrini, E. M., Zacchi, P., Barberis, A., Mozrzymas, J. W., and Cherubini, E. (2003). Declusterization of GABAA receptors affects the kinetic properties of GABAergic currents in cultured hippocampal neurons. J. Biol. Chem. 278, $16271-16279$.

Piechotta, K., Weth, F., Harvey, R. J., and Friauf, E. (2001). Localization of rat glycine receptor alpha1 and alpha2 subunit transcripts in the developing auditory brainstem. J. Comp. Neurol. 438, 336-352.

Raiteri, L., Raiteri, M., and Bonanno, G. (2001). Glycine is taken up through GLYT1 and GLYT2 transporters into mouse spinal cord axon terminals and causes vesicular and carrier-mediated release of its proposed co-transmitter GABA. J. Neurochem. $76,1823-1832$

Rampon, C., Luppi, P. H., Fort, P., Peyron, C., and Jouvet, M. (1996). Distribution of glycine-immunoreactive cell bodies and fibers in the rat brain. Neuroscience 75 , 737-755.

Rigo, J. M., Badiu, C. I., and Legendre, P. (2003). Heterogeneity of postsynaptic receptor occupancy fluctuations among glycinergic inhibitory synapses in the zebrafish hindbrain. J. Physiol. 553, 819-832.

Rigo, J. M., and Legendre, P. (2006). Frequency-dependent modulation of glycine receptor activation recorded from the zebrafish larvae hindbrain. Neuroscience 140 389-402.

Robinson, H. P., and Kawai, N. (1993). Single channel properties at the synaptic site. EXS 63, 250-265.

Rossi, D. J., and Hamann, M. (1998). Spillover-mediated transmission at inhibitory synapses promoted by high affinity alpha6 subunit GABA(A) receptors and glomerular geometry. Neuron 20, 783-795.

Rusakov, D. A., and Kullmann, D. M. (1998). A tortuous and viscous route to understanding diffusion in the brain. Trends Neurosci. 21, 469-470.

Russier, M., Kopysova, I. L., Ankri, N., Ferrand, N., and Debanne, D. (2002). GABA and glycine co-release optimizes functional inhibition in rat brainstem motoneurons in vitro. J. Physiol. 541, 123-137.

Sagné, C., El Mestikawy, S., Isambert, M. F., Hamon, M., Henry, J. P., Giros, B., and Gasnier, B. (1997). Cloning of a functional vesicular GABA and glycine transporter by screening of genome databases. FEBS Lett. 417, 177-183.

Salin, P. A., and Prince, D. A. (1996). Spontaneous GABAA receptor-mediated inhibitory currents in adult rat somatosensory cortex. J. Neurophysiol. 75, 1573-1588.

Sassoè-Pognetto, M., Kirsch, J., Grünert, U., Greferath, U., Fritschy, J. M., Möhler, H., Betz, H., and Wässle, H. (1995). Colocalization of gephyrin and GABAA-receptor subunits in the rat retina. J. Comp. Neurol. 357, 1-14.

Sato, K., Kiyama, H., and Tohyama, M. (1992) Regional distribution of cells expressing glycine receptor alpha 2 subunit mRNA in the rat brain. Brain Res. 590, 95-108.

Scanziani, M. (2000). GABA spillover activates postsynaptic GABA(B) receptors to control rhythmic hippocampal activity. Neuron 25, 673-681.

Singer, J. H., Talley, E. M., Bayliss, D. A., and Berger, A. J. (1998). Development of glycinergic synaptic transmission to rat brain stem motoneurons. J. Neurophysiol. $80,2608-2620$.

Smith, A. J., Owens, S., and Forsythe, I. D. (2000). Characterisation of inhibitory and excitatory postsynaptic currents of the rat medial superior olive. J. Physiol. 529, 681-698.

Sokolova, E., Nistri, A., and Giniatullin, R. (2001). Negative cross-talk between anionic GABAA and cationic P2X ionotropic receptors of rat dorsal root ganglion neurons. J. Neurosci. 21, 4958-4968.

Stórustovu, S. I., and Ebert, B. (2006). Pharmacological characterization of agonists at delta-containing GABAA receptors: functional selectivity for extrasynaptic receptors is dependent on the absence of gamma2. J. Pharmacol. Exp. Ther. 316 1351-1359.

Sur, C., McKernan, R., and Triller, A. (1995). Subcellular localization of the GABAA receptor gamma 2 subunit in the rat spinal cord. Eur. J. Neurosci. 7, 1323-1332.

Takagi, T., Pribilla, I., Kirsch, J., and Betz, H. (1992). Coexpression of the receptor-associated protein gephyrin changes the ligand binding affinities of alpha 2 glycine receptors. FEBS Lett. 303, 178-180.

Takahashi, T., Momiyama, A., Hirai, K., Hishinuma, F., and Akagi, H. (1992). Functional correlation of fetal and adult forms of glycine receptors with developmental changes in inhibitory synaptic receptor channels. Neuron 9, 1155-1161.

Taleb, 0., and Betz, H. (1994). Expression of the human glycine receptor alpha 1 subunit in Xenopus oocytes: apparent affinities of agonists increase at high receptor density. EMBO J. 13, 1318-1324.

Titmus, M. J., Korn, H., and Faber, D. S. (1996). Diffusion, not uptake, limits glycine concentration in the synaptic cleft. J. Neurophysiol. 175, 1738-1752.

Toulmé, E., Blais, D., Léger, C., Landry, M., Garret, M., Séguéla, P., and Boué-Grabot, E. (2007). An intracellular motif of $P 2 X(3)$ receptors is required for functional crosstalk with $\operatorname{GABA}(A)$ receptors in nociceptive DRG neurons. J. Neurochem. 102, $1357-1368$

Triller, A., and Choquet, D. (2005). Surface trafficking of receptors between synaptic and extrasynaptic membranes: and yet they do move! Trends Neurosci. 28, 133-139.

Trombley, P. Q., Hill, B. J., and Horning, M. S. (1999). Interactions between GABA and glycine at inhibitory amino acid receptors on rat olfactory bulb neurons. J. Neurophysiol. 82, 3417-3422. 
Unwin, N. (1993). Neurotransmitter action: opening of ligand-gated ion channels. Cell $72,31-41$.

Vannier, C., and Triller, A. (1997). Biology of the postsynaptic glycine receptor. Int. Rev. Cytol. 176, 201-244.

Wall, M. J., and Usowicz, M. M. (1997). Development of action potential-dependent and independent spontaneous GABAA receptor-mediated currents in granule cells of postnatal rat cerebellum. Eur. J. Neurosci. 9, 533-548.

Webb, T. I., and Lynch, J. W. (2007). Molecular pharmacology of the glycine receptor chloride channel. Curr. Pharm. Des. 13, 2350-2367.
Wisden, W., Laurie, D. J., Monyer, H., and Seeburg, P. H. (1992). The distribution of 13 GABAA receptor subunit $\mathrm{mRNAs}$ in the rat brain. I. Telencephalon, diencephalon, mesencephalon. J. Neurosci. 12, 1040-1062.

Yakel, J. L. (1997). Calcineurin regulation of synaptic function: from ion channels to transmitter release and gene transcription. Trends Pharmacol. Sci. 18 , 124-134.

Zou, S., Li, L., Pei, L., Vukusic, B., Van Tol, H. H., Lee, F. J., Wan, Q., and Liu, F. (2005) Protein-protein coupling/uncoupling enables dopamine D2 receptor regulation of AMPA receptor-mediated excitotoxicity. J. Neurosci. 25, 4385-4395. 